\title{
Giant congenital melanocytic nevus associated with lipoma
}

\section{Rhizlane Chaoui, Hanane Baybay, Selma El Kadiri, Kaoutar Achehboune, Zakia Douhi, Sara Elloudi, Fatima Zahra Mernissi}

Department of Dermatology, University Hospital Hassan II, Fez, Morocco

Corresponding author: Dr. Rhizlane Chaoui, E-mail: chaoui.rhizlane@gmail.com

\begin{abstract}
Giant congenital melanocytic nevi (GCMN) are rare conditions that defined as a benign proliferation of melanocytic cells; present at birth. Their incidence varies between $1 / 200000$ and $1 / 500000$ of newborns. Despite its rarity. There is a significant association with severe abnormalities like spina bifida occulta, meningocele, club foot and hypertrophy or atrophy of deeper structures of a limb, Carney complex, premature aging syndromes, neurofibroma, vitiligo, lipoma and dysplasia of bilateral hip. We report a 9-year-old girl child presenting a GCMN associated with lipoma.
\end{abstract}

Key words: Giant congenital melanocytic nevi; Lipoma; Dermoscopy

\section{INTRODUCTION}

Congenital melanocytic nevi (CMN) are defined as melanocytic nevi present at birth or shortly thereafter. Giant congenital melanocytic nevus is a variant of congenital melanocytic nevus, it is defined as melanocytic nevus measuring more than $20 \mathrm{~cm}$ in its greatest dimension. Patients with giant $\mathrm{CNN}$ are at a significantly increased risk for the development of malignant melanoma, and should be kept under continuous surveillance [1].

GCMN have been described to be associated with spina bifida occulta, neurofibromatosis, lipomatosis, and various other disorders.

We present a case of GCMN associated with lipoma.

\section{CASE REPORT}

A healthy 9-year-old girl was born with a circumferential giant congenital melanocytic nevus that involved the entire abdomen, back, bilateral groins, buttocks, and left thigh with some areas of healthy skin and hypertrichosis. The nevus had a homogeneous dark brown color, rugose surface and consistency similar to normal skin (Figs. la and lb), associated with a satellite lesions represented by multiple pigmented macules and papules of variable size dispersed in the face, palmo-plantar area and limbs (Figs. 2a and 2b).

Dermoscopy revealed a homogeneous pigmentation, perifollicular hypopigmentation and homogeneous globular pattern (Fig. 3).

The girl also had a lesion, measuring about $4 \mathrm{~cm}$ in diameter, on the lateral side of left lumbar area covered by the GCMN (Fig. 4). An echography of the soft parts was performed.

After performing surgical excision, the lesion was diagnosed as lipoma.

\section{DISCUSSION}

Giant congenital nevi also known as garment nevus or giant hairy nevus are defined as a benign proliferation of melanocytic cells; present at birth which measure greater than $20 \mathrm{~cm}$ in their largest diameter. The incidence is rare around 1 per 500,000 newborns [1].

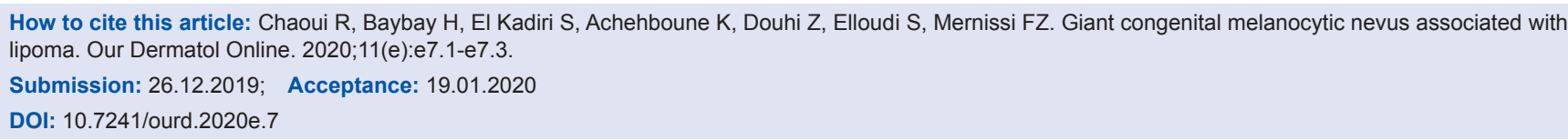




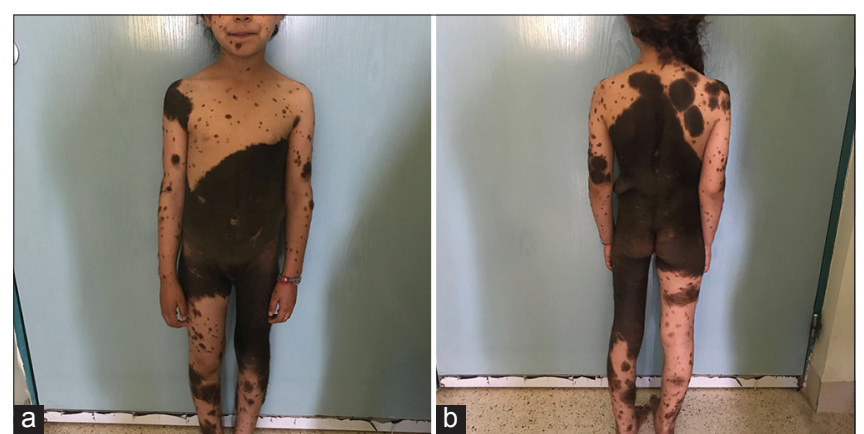

Figure 1: $a$ and b: Giant melanocytic nevus on trunk and extremities with dark brown coloration and hypertrichosis.

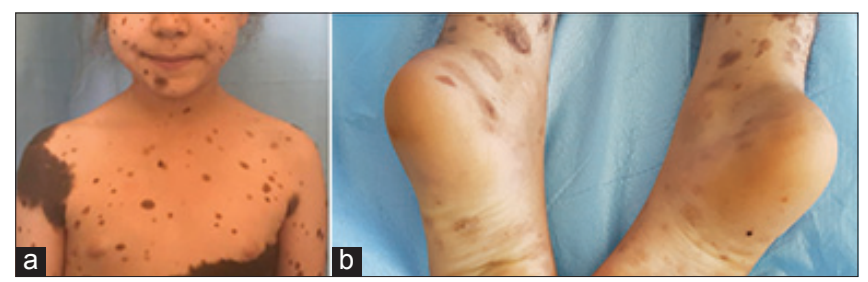

Figure 2: $a$ and b: Satellite lesions on the face and plantar areas.

Giant congenital nevus have a clinical polymorphism, they are usually flat, varying in color from light brown to dark. The surface of the nevus may be smooth, rugose, and nodular with terminal hairs. They have sometimes the particularity of presenting a proliferation nodules or hamartomatous lesions [2]. They are commonly present in trunk, followed by the limbs and the head.

The diagnosis is essentially clinical. Para clinic explorations are requires in front of any suspicion of complications, particularly the malignant melanoma and the neuro-cutaneous melanosis (RMI) [3].

The dermoscopic finding include: homogenuous pigmentation, target globues target vessels, or perifollicular hypopigmentation.

The treatment of giant congenital melanocytic nevus include surgical and non-surgical procedures, psychological intervention (due to its unsightly appearance) and especially clinical follow-up.

Various associated abnormalities have been reported with giant CMN. The documented associations are with neurocutaneous melanocytosis, spina bifida occulta, meningocoele, club foot, neurofibromatosis, lipomatosis, and hypertrophy and atrophy of limbs. There have been few reports of epidermal nevus syndrome, Carney complex, premature aging syndromes, and ambiguous genitalia association with GCMN [4].

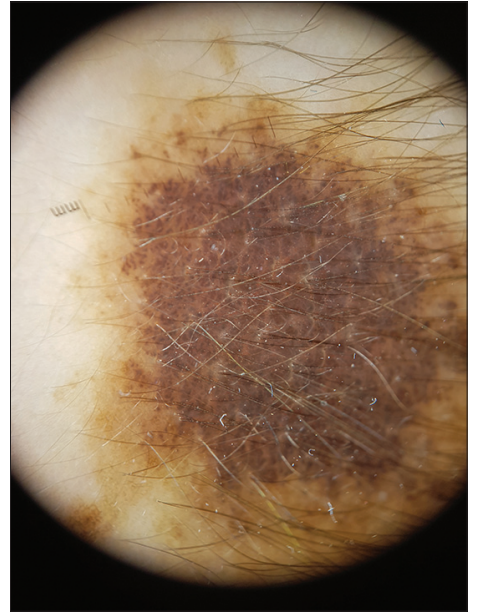

Figure 3: Homogeneous pigmentation and globular pattern with perifollicular hypopigmentation.

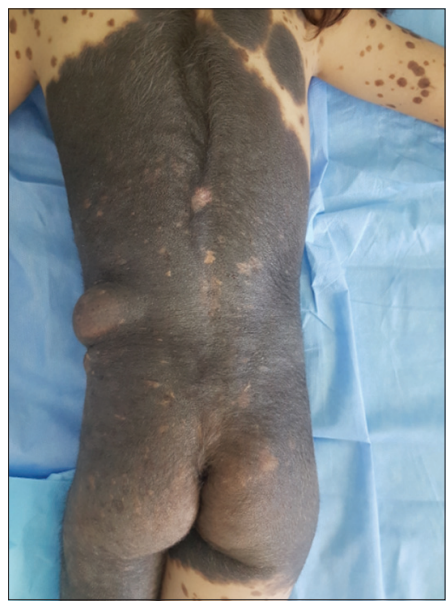

Figure 4: Lipoma measuring about $4 \mathrm{~cm}$ in diameter, on the lateral side of left lumbar area covered by the GCMN.

These associations may probably be due to a defect in the neural crest, which is considered to be a common origin of melanoblasts, Schwann cells, sensory ganglia, bone, fat, muscle and blood vessels.

In a study done on agouti mouse, The authors conclude that largely independent of changes in food intake, the central nervous melanocortin system directly and rapidly controls triglyceride synthesis, lipid deposition and lipid mobilization in white adipose tissue.All this may explain the occurrence of lipoma in giant congenital melanocytic nevus [5].

\section{CONCLUSION}

Giant congenital nevi are exceptional with an unpleasant prognosis. We described a rare association of Giant Congenital Melanocytic Nevus and lipoma, which remains possible. 


\section{Consent}

The examination of the patient was conducted according to the Declaration of Helsinki principles.

The authors certify that they have obtained all appropriate patient consent forms. In the form the patient(s) has/have given his/her/their consent for his/her/their images and other clinical information to be reported in the journal. The patients understand that their names and initials will not be published and due efforts will be made to conceal their identity, but anonymity cannot be guaranteed.

\section{BIBLIOGRAPHY}

1. Vourc'h-Jourdain M, Martin L, Barbarot S, aRED. Large congenital melanocytic nevi: therapeutic management and melanoma risk. A systematic review. J Am Acad Dermatol. 2013;68:493-8.e1-14.
2. Tannous ZS, Mihm MC Jr, Sober AJ, Duncan LM. Congenital melanocytic nevi: Clinical and histopathologic features, risk of melanoma, and clinical management. J Am Acad Dermatol. 2005;52:197-203.

3. Marghoob AA, Schoenbach SP, Kopf AW, Orlow SJ, Nossa R, Bart RS. Large congenital melanocytic nevi and the risk for the development of malignant melanoma. A prospective study. Arch Dermatol 1996;132:170-5.

4. Marghoob AA, Orlow SJ, Kopf AW. Syndromes associated with melanocytic nevi. J Am Acad Dermatol. 1993;29:373-88.

5. Bhagwat P, Tophakhane R, Shashikumar B., Noronha T, Naidu V. Giant congenital melanocytic nevus (bathing trunk nevus) associated with lipoma and neurofibroma: Report of two cases. Indian J Dermatol Venereol Leprol. 2009;75:495.

Copyright by Rhizlane Chaoui, et al. This is an open-access article distributed under the terms of the Creative Commons Attribution License, which permits unrestricted use, distribution, and reproduction in any medium, provided the original author and source are credited.

Source of Support: Nil, Conflict of Interest: None declared. 